\title{
Futebol: entre o lazer e o controle
}

Agnaldo KUPPER*

RESUMO: O futebol moderno vincula-se ao industrialismo. Arrisco afirmar que a vida humana ocidental contemporânea aparenta partidas de futebol: embates, tempo medido, lutas pela titularidade e aceitação, torcidas agindo como partidos políticos, discussões de teses, improvisos, simbologias de socialização, teatralização da vida social, entre outros. Faz-se necessário entender como o brasileiro apropriou-se do esporte, como que o tomando das camadas mais abastadas que o introduziram no país. Nas primeiras décadas do século XX, o movimento operário brasileiro postou-se de forma ruidosa. A nascente burguesia industrial brasileira, inquieta diante das mobilizações sindicais proletárias, teria feito uso de mecanismos menos duros como apoiar e financiar o esporte que caíra nas graças operárias: o futebol. $\mathrm{O}$ resgate histórico-social de documentos de diversas agremiações permite observar interferências patronais no desenvolvimento clubista, controlando-as direta e/ou indiretamente. De lá para cá, o esporte seguiu sua trajetória, permeando políticas e ajustando conflitos pessoais.

PALAVRAS-CHAVE: Futebol. Industrialismo. Controle social.

\section{Introdução}

O processo de urbanização vivido na segunda metade do século XIX na Inglaterra relaciona-se com o processo de proletarização do futebol.

A febre futebolística vivida na Inglaterra a partir da segunda metade do século XIX espalhou-se pelos mais diversos cantos britânicos (escolas fábricas, portos e

UNESP - Universidade Estadual Paulista "Júlio de Mesquita Filho". Faculdade de Ciências e Letras de Assis. Programa de Pós-graduação em História. Assis - SP - Brasil. 1906900. agnaldokupper2009@ hotmail.com. https://orcid.org/0000-0001-7547-2334. 
ferrovias) e do planeta, encontrando no continente americano um de seus campos mais férteis.

O futebol enquanto modalidade esportiva é popular em vários cantos do mundo. Porém, a forma como se desenvolveu no Brasil tem alto grau de peculiaridade. Em realidade, as cidades de São Paulo-SP e Rio de Janeiro-RJ assumiram o papel de destaque no futebol desde o início do século XX, independentemente do pioneirismo da prática. A primeira pelo desempenho econômico; a segunda por ser o centro político do país.

À medida que o processo industrial avançou no país, associações de resistência procuraram organizar os trabalhadores em torno da luta pela defesa de seus interesses materiais e morais ameaçados pela exploração do trabalho. Nesse contexto, o futebol de fábrica surgiu como passatempo. Aos poucos, outros interesses brotaram, com empresários descobrindo na prática a possibilidade de se obter disciplina, controle sobre o tempo dos trabalhadores das fábricas, cerceamento sobre as atividades dos trabalhadores nos sindicatos, valorização de seus produtos e artigos, visualização positiva da empresa, além da imagem de preocupação com a condição física e de lazer de seus colaboradores.

Importa, por isso, perceber como o povo brasileiro apropriou-se do esporte, como que tomando-o das camadas mais abastadas que o introduziram no país. Para atingir esse objetivo foram analisados jornais, atas, balancetes e periódicos diversos, utilizando-os como fontes primárias. A documentação obtida nos arquivos dos clubes, tal como cartas, relatórios, circulares e estatutos, atestam investimentos de empresas em práticas esportivas como o futebol. Afinal, vale lembrar que o número de clubes de futebol no Brasil nas primeiras décadas do século XX não parou de crescer. Criados por trabalhadores, muitas dessas agremiações buscaram apoio para suas atividades junto às direções patronais, apoio este material e financeiro, como cessão de terreno para estruturação de campo e sede, material de jogo, aluguéis, uniformes, deslocamentos dos praticantes, bolas, entre outros. Não sem intenções.

\section{Futebol e Industrialismo}

Futebol, atletismo, remo, turfe, pugilismo. Eis alguns dos esportes originados na Inglaterra. A princípio, de caráter excludente, praticados por indivíduos das camadas sociais mais abastadas.

A penetração de tais práticas entre as demais camadas sociais inglesas significou a consolidação de novos hábitos culturais, a que Pierre Bourdieu (1997) denomina violência simbólica, apontando à adesão de um conjunto de hábitos e práticas representativas que definem certo estilo de vida. "A violência simbólica 
consiste em uma violência que se exerce com a cumplicidade tácita dos que a sofrem e também, com frequência, dos que a exercem, na medida em que uns e outros são inconscientes de exercê-la ou de sofrê-la". (BOURDIEU, 1997, p.22).

Ou seja, Bourdieu (1997) entende o esporte moderno como um fenômeno em que são atribuídas posições relacionadas ao capital social, econômico e cultural de cada agente. A busca da hegemonia de determinadas práticas seria o acúmulo de uma distinção social de acordo com o seu potencial de poder simbólico. Segundo Bourdieu (1997), para se compreender o esporte seria necessário conhecer e reconhecer a posição que determinada atividade desportiva ocupa por meio da distribuição dos praticantes de acordo com a posição do mesmo no espaço social, apontando para a necessidade de se perceber o tratamento da prática na condição de fenômeno inscrito em um sistema mercadológico. Marivoet (2013) reforça os entendimentos de Bourdieu (1997) ao estabelecer que práticas e gostos culturais são indicadores da condição do indivíduo em uma estrutura social, incluindo aí os hábitos esportivos.

A popularização dos esportes citados - entre os quais o futebol que, em tempos contemporâneos, abandona progressivamente seu caráter recreativo para transformar-se em atividade vinculada ao consumo de massa - fundamenta-se (não só, mas acima de tudo) em relações capitalistas. Segundo Mariovet (2002), o desporto moderno vincula-se às transformações vividas pelas sociedades, satisfazendo necessidades sociais e desempenhando um papel educativo nas mesmas. Para Hilário Franco Júnior (2007), os esportes modernos devem ser observados no âmbito do darwinismo social, ou seja, como espaço de organização das elites para tornarem-se referência a outros setores sociais.

Segundo Bero Rigauer (1969), o esporte é uma adaptação à vida moderna, consistindo como forma dissimulada para o trabalho, reproduzindo, em si, o mundo do capitalismo por ter em sua constituição autoridade, concorrência, competência, aperfeiçoamento, organização e burocracia.

Aponto, para a proliferação dos esportes modernos (caso, em especial, do futebol), fatores como o nacionalismo, interesses científicos e a cultura de massa. Porém, o destaque à popularização do futebol também deve ser atribuído à facilidade de praticá-lo.

Não é de se estranhar o desenvolvimento do esporte moderno na linha da trajetória do capitalismo em sua fase industrial: racionalização, padronização e cálculo de performance, acompanhando a transição para a vida de base urbanoindustrial (competitiva, racional e marcada pela busca de eficiência), expressando a passagem para uma nova mentalidade social, enraizada entre membros sociais privilegiados (até pela disponibilidade de tempo livre entre membros de uma elite social), em seguida internalizada entre os trabalhadores (até como forma de reforço às mentalidades dos segmentos sociais dominadores). 
Thompson (1987) afirma que seria ilusão imaginar que a Revolução Industrial (tanto a Primeira quanto a Segunda) substituiria o mundo rural por um mundo urbano sem conflitos.

No contexto da urbanização trazido pelo processo revolucionário industrial, a educação passou a adquirir status de treinamento para o hábito do trabalho, com destaque à pontualidade e ao estabelecimento de regras rígidas.

Thompson (1998) formula hipóteses para a passagem da valorização do tempo natural para o tempo das fábricas.

A primeira geração de trabalhadores nas fábricas aprendeu com seus mestres a importância do tempo; a segunda geração formou os seus comitês em prol de menos tempo de trabalho, no movimento pela jornada de dez horas; a terceira geração fez greves pelas horas extras ou pelo pagamento de um percentual adicional pelas horas trabalhadas fora do expediente. [...] Haviam aprendido muito bem a sua lição, a de que tempo é dinheiro. (THOMPSON, 1998, p.294).

Assim sendo, os esportes modernos surgiram na transição para o industrialismo pleno, com práticas como o futebol, o basquete e o vôlei respondendo às novas circunstâncias urbanas e disciplinares da segunda metade do século XIX, quando o tempo cronométrico passou a ser fator para avaliações do desempenho, o que significa dizer que o espírito profissional passou a superar o espírito lúdico como forma de recuperação da energia disponibilizada para o trabalho através do entretenimento. A penetração do futebol enquanto atividade entre trabalhadores talvez - mesmo que inconscientemente - tenha tido como razão a possibilidade destes de recuperarem o que lhes foi retirado pela linha de produção fabril, trazendo-lhes a sensação de pertencimento de si e não à fábrica, com um importante ingrediente: levar o trabalhador a discuti-lo como forma de subtração do foco da exploração.

Sobre a origem do esporte moderno, Elias e Dunning (1992a, p.225) afirmam que há uma relação íntima entre industrialização e esportivização, própria "de uma transformação mais profunda das sociedades europeias, o que exigia dos seus membros uma maior regularidade e diferenciação de comportamentos".

Não se deve estranhar a multiplicação das regras esportivas a partir do século XVIII, em plena fase da explosão revolucionária produtiva industrial: corridas de cavalo, 1750; golfe, 1751; críquete, 1788; rúgbi, 1846; ciclismo, 1868; futebol, 1863. Isto porque Revolução Industrial e futebol (entre outros esportes) baseiase na competição, na produtividade, especialização de funções e quantificação de resultados.

Norbert Elias e Eric Dunning (1992b) identificam na organização do esporte um elemento do processo de pacificação social, uma vez que por meio dele os 


\section{Futebol: entre o lazer e o controle}

componentes de uma sociedade abrem mão de resolver diferenças aceitando as regras para uma disputa em que não haverá feridos ou mortos, pelo menos reais:

As condições que propiciavam a emoção forte, sobretudo a emoção socialmente compartilhada que poderia levar à perda do autocontrole, se fizeram então mais raras e menos toleráveis do ponto de vista social. O problema estava em como dar aos indivíduos a oportunidade de experimentar plenamente a excitação agradável que parece ser uma das necessidades mais elementares dos seres humanos sem os conseguintes perigos sociais e pessoais para os outros ou para si mesmos (ELIAS; DUNNING, 1992b, p.204).

Ainda de acordo com Elias e Dunning (1995, p.64), as sociedades humanas procuram compensar as tensões acumuladas dos indivíduos (afinal, a tendência humana é querer chutar, agredir com o pé o que vemos como possível ou o que se mostra à nossa frente, talvez daí a necessidade do futebol para nos disciplinar), sendo o esporte uma das principais atividades de satisfazer impulsos instintivos, emocionais e afetivos cerceados pelas regras sociais, liberando tensões provocadas pelo esforço da pessoa em conter-se.

Neste sentido, foi nos anos finais do século XVIII, com a consolidação do parlamentarismo e a Revolução Industrial, representando a vitória do capitalismo na sociedade inglesa, que começaram a ocorrer mudanças no jogo de bola.

O futebol, esporte que vincula disciplina e solidariedade, serviria ao propósito.

Com a finalidade de disciplinar o jogo, regras fixas deveriam ser criadas. Em 26 de outubro de 1863, surgiu o chamado football association (futebol moderno), quando representantes de onze clubes e escolas reuniram-se e fundaram a Football Association, em Londres (acredita-se que o número de onze jogadores tenha sido definido a partir dos onze representantes reunidos). Nesse mesmo ano, o futebol foi codificado em apenas quatorze regras (atualmente, são dezessete), tornadas públicas em livros e cartilhas distribuídas pelo país. Como as discussões mantinham-se, necessária a introdução de um árbitro. Estabeleceu-se, ainda, que os jogos deveriam ser decididos por gols, com prorrogações até que houvesse desempate (NORONHA, 1975, p.294). Ao que consta, as regras do futebol vinculam-se ao parlamentarismo, onde o poder não está concentrado apenas em um indivíduo, mas é dividido entre setores sociais rivais, o que exige negociação e revezamento dos grupos através de leis, porém com regras de conduta e participação. As regras definidas procuraram pressupor a igualdade de condições entre os competidores.

O futebol proliferou, chegando à França em 1872, à Suíça em 1879, à Bélgica em 1880, à Holanda, Dinamarca e Alemanha em 1889, à Itália em 1893, ao Brasil em 1895 (de forma oficial). Na América Latina, a rápida propagação da modalidade 
foi facilitada pelo fato de existirem no continente comunidades inglesas ligadas a empresas e empreendimentos do capitalismo inglês (AQUINO, 2002).

Ou seja, a difusão do futebol seguiu a influência cultural inglesa: num primeiro momento a proliferação da prática nas ilhas britânicas; em seguida, na Europa germânica, chegando posteriormente à Europa Latina e América Latina (no Brasil, embora mais enraizado em São Paulo e Rio de Janeiro - próprio dos maiores investimentos britânicos - espalhou-se simultaneamente por vários pontos de seu território) (FRANCO JUNIOR, 2007).

\section{No Brasil, a apropriação do futebol como forma de controle sobre os trabalhadores}

Para Antunes (1994), foi no ambiente das fábricas que o futebol ganhou corpo e estrutura, com os trabalhadores, na busca de lazer, criando soluções para praticar o esporte.

Inúmeros clubes surgiram de partidas de futebol improvisadas na rua ou no pátio da fábrica, durante o intervalo para o almoço. Aos poucos, a brincadeira ia ganhando organização. Como muita gente queria participar, os times começaram a ser formados no interior de cada seção de uma mesma indústria. Com o crescimento do número de times, mais partidas iam sendo realizadas, aumentando o tempo do jogo. Logo, só o intervalo para o almoço já não bastava. Estendeu-se, então, a atividade para os fins de semana (ANTUNES, 1994, p.104).

No Rio de Janeiro foi criada, em 1892, a Companhia Progresso Industrial do Brasil (Fábrica de Tecidos Bangu). A mesma conheceu algumas greves que a paralisaram: em 1894, 1896 e em 1903 (neste último ano, o movimento atingiu outras fábricas do Rio de Janeiro - reclamatória da alta jornada de trabalho imposta aos trabalhadores e por melhores salários - e envolveu dezoito mil e setecentos trabalhadores da capital federal ${ }^{1}$ ).

No caso específico da Companhia Progresso Industrial do Brasil, a paralisação de 1903 teve motivos próprios: diminuição salarial dos funcionários da empresa, elevação dos aluguéis das casas que formavam a Vila Operária local (que chegou a ter trezentas residências erguidas como forma de abatimento na incidência de impostos), atrasos salariais e elevação dos preços dos gêneros alimentícios comercializados localmente por negociantes estabelecidos com autorização da companhia (vale lembrar que o bairro de Bangu, onde se situava a Companhia,

Jornal O Paiz, 22 de Agosto de 1903, p.2. 
mostrava-se como uma espécie de fábrica-fazenda, distante do centro do Rio de Janeiro).

Além das greves, a Fábrica Bangu assistiu, em seus primeiros anos, a embates entre brasileiros e imigrantes. Entre 1899 e 1901, trabalharam na empresa dezenove ingleses, setenta e um portugueses, treze espanhóis, seis franceses, oitenta e seis italianos, nove alemães, vinte russos e oito trabalhadores de outras nacionalidades ${ }^{2}$. Normalmente, os desentendimentos foram de caráter pessoal e particular.

Por ocasião da greve de 1903, o diretor-presidente da Companhia Progresso, o luso Eduardo Gomes Ferreira, pediu exoneração do cargo em 17 de agosto do mesmo ano. Desta forma, foi elevado a condição de diretor-gerente interino o tesoureiro espanhol João Ferrer, que adotou um estilo paternalista ao procurar criar um espírito solidário entre os diversos trabalhadores do empreendimento.

Com Ferrer na direção, os mestres têxteis ingleses foram atendidos em uma antiga reivindicação: a fundação de um clube de futebol, nos moldes do existente em seu país de origem. Ferrer entendeu que o futebol (ainda uma novidade no Brasil), poderia servir para unir os trabalhadores.

De acordo com as intenções da Companhia Progresso, surgiu o Bangu Athetic Club (primeiro clube de fábrica do Brasil), em 17 de abril de 1904. Reuniramse dez chefes de seções empresa (oito ingleses, um italiano e um português). A princípio, poucos empregados foram aceitos no novo clube, prevalecendo os funcionários especializados de origem estrangeira.

De início, o clube congregava parcelas muito restritas dos empregados da fábrica, compondo-se somente de trabalhadores especializados de origem estrangeira, que ocupavam cargos de chefia. [...] A necessidade de apoio por parte da fábrica fez, porém, com que os fundadores do clube logo ampliassem esse impulso inicial, atendendo aos interesses da Companhia (PEREIRA, 2000, p.32).

A necessidade de apoio para a manutenção do futebol na fábrica - até pelo número de praticantes que se mostrava reduzido, impedindo, muitas vezes, a formação de times - fez com que fosse aberta a participação de operários de outras origens $^{3}$. O valor para o ingresso (joia) foi estipulado em $2 \$ 000$ e o da mensalidade em $1 \$ 000$, como forma de angariar trabalhadores de origem mais humilde (a título de comparação, o Fluminense, altamente elitizado, cobrava mensalidade de $5 \$ 000)^{4}$.

2 Relatório da Assembleia Geral Ordinária da Companhia Progresso Industrial do Brasil, realizada em 02 de Abril de 1903.

3 Ata da sessão de 17 de abril de 1904

4 O padrão da moeda no Brasil, foi, até 1942, o mil-réis. Um mil-réis era escrito como $1 \$ 000$. Usava-se o conto para indicação de grande quantidade de dinheiro. Um conto equivalia a 1 mil réis $(1 \$ 000.000)$. 
O Bangu distingue-se de outros clubes do Rio de Janeiro por ser o precursor da democratização do acesso às práticas futebolísticas, por ter sido o primeiro time operário do Rio de Janeiro, por ter dado aos jogadores-operários privilégios (abono de faltas e garantia de emprego, por exemplo), por receber por parte da diretoria certo paternalismo da Companhia Progresso e por iniciar a subordinação à vigilância das ações operárias, demonstrando dependência e o interesse dos trabalhadores em fazer parte de uma elite operária. Em pouco tempo, o futebol tornou-se a grande opção de lazer daquela comunidade 5 .

O campo do Bangu transformou-se em um quintal da fábrica, uma espécie de continuidade do espaço de trabalho (PEREIRA, 2000, p.259). Normal, desta forma, que a direção da Companhia Progresso o tratasse como um departamento, sendo feita a cessão de terreno, de móveis e de utensílios para o clube, além de uniformes e incentivo à promoção de festivais entre os seus sócios ${ }^{6}$.

Para ser sócio do Bangu, foi estabelecido em assembleia que o pretendente deveria ser empregado da Companhia Proresso. Caso saísse da empresa por comportamento inadequado, o então associado deveria "deixar o quadro da associação" .

Rosenfeld (1993), ao analisar o caso do Bangu Athletic Club, apresenta a hipótese de que o incentivo do futebol entre os operários:

[...] seria uma forma de domesticar seus corpos para o trabalho e infundir neles um sentimento de grupo, identificado com a empresa. Em virtude da distância do subúrbio, entretanto, não foi possível aos ingleses (empregados da Fábrica Bangu) constituírem equipes fechadas chamando os compatriotas da cidade. Viram-se obrigados a recorrer aos operários da fábrica. (ROSENFELD, 1993, p.61).

Com a apreciação contínua da prática, a direção da Fábrica Bangu passou a conceder privilégios aos bons jogadores-operários, como trabalho mais leve, promoções e licenças especiais para treinamentos. Aos poucos, o futebol do Bangu tornou-se mais famoso que a fábrica em si.

Em 1906, Ferrer cedeu um campo de futebol ao Bangu AC num terreno da fábrica para que a associação disputasse o Primeiro Campeonato Carioca.

Por ocasião da realização do Primeiro Congresso Operário Brasileiro, em 1906, decidiu-se por uma campanha por oito horas de trabalho. A Fábrica Bangu, com seus 1651 trabalhadores, não abraçou a causa. Para o dia do Congresso, 01 de maio, Ferrer promoveu a inauguração de um jardim na Fábrica Bangu, seguida de um jogo de futebol entre o Bangu e o Esperança. Segundo o editorial do Jornal

5 "Gazeta dos Sports", Gazeta de Notícias, 12 de setembro de 1907.

6 Ata da Sessão de 21 de janeiro de 1915 e Ata da Sessão de 10 de fevereiro de 1916. Livro de Ata do Bangu AC.

7 Ata da Sessão de 24 de abril de 1904, Livro de Atas do Bangu AC. 
Gazeta de Notícias, na maior fábrica do Rio de Janeiro os operários não tinham nada a reivindicar, mas a agradecer ${ }^{8}$.

Em 24 de Agosto de 1909, foi entregue pela direção da Fábrica Bangu, uma sede social à associação do Bangu AC.

Com suas ações, João Ferrer teria conseguido controlar o operariado da Companhia Progresso, afastando-o das discussões e reivindicações dos trabalhadores do período. Contava, ainda com o apoio da imprensa escrita, exaltadora de seus feitos. Críticas apenas da imprensa operária através do Jornal $A$ Voz do Trabalhador:

[...] Como a imprensa não se cansa de agitar o seu turúbulo, incensando a benemerência dos senhores de Bangu, tivemos vontade de conhecer a fábrica. [...] A situação era igual ou pior do que a de outras fábricas. Não havia liberdade, mas havia uma forte depressão mental para fazer esquecer e até louvar o cativeiro. ${ }^{9}$

No caso do Bangu, mais do que combater o sindicalismo, o futebol serviu para unir empregados de nacionalidades diferentes, funcionando como elemento de união e pertencimento. Tanto que em Bangu foram também incentivadas outras modalidades esportivas como o tênis e o críquete $^{10}$.

Os Estatutos do Bangu AC apontaram ser dever dos sócios " [...] a condução com a máxima correção quando uniformizados ou com o distintivo do $c l u b \mathrm{e}$ quando estiverem no recinto deste. Os sócios serão censurados pela diretoria; na reincidência, suspensos ou eliminados." 11

O futebol serviu, sim, para unir operários da Fábrica Bangu, mas não parece ter gerado uma consciência de classe. O Artigo 50 dos Estatutos do Bangu AC de 1915 desqualificava tal propósito ao prever ser "[...] expressamente proibidas, no recinto do $c l u b$, as discussões de caráter político, religioso ou de nacionalidade."12

Um jogador de futebol de destaque do Bangu normalmente ascendia na fábrica, obtendo cargo mais elevado e salário maior.

\section{O Bangu AC fez escola}

Para Cláudio Batalha (2004, p.114), entre as indústrias têxteis "os clubes transformaram-se em mais um dos mecanismos de controle da empresa sobre seus empregados".

\footnotetext{
8 Jornal Gazeta de Notícias, 05 de Maio de 1906.

9 Jornal A Voz do Trabalhador, 15 de Junho de 1909, p.1.

10 "Ata da Sessão de 17 de Abril de 1904". Livro 1 de Atas das Sessões da Diretoria do Bangu AC, 17 de Abril de 1904 a 07 de Fevereiro de 1905.

${ }_{11}$ Estatutos do Bangu AC aprovados em Assembleia Geral realizada em 20 de Abril de 1915, p.3.

12 Estatutos do Bangu AC, 1915, p.10.
} 
Muitas associações de futebol passaram a ter em seus quadros membros das diretorias das unidades produtivas, até como forma de se obter auxílio financeiro em caso de necessidade ${ }^{13}$. Tê-los também era uma forma de se obter legitimidade dos clubes e seus sócios junto às autoridades policiais (BRETAS, 1997), da mesma forma que a ação, ao que consta, diminuía a distância e as contradições entre empregados e empregadores.

Paulatinamente, ao ver o futebol ganhar apreço entre populares, propagandas industriais e de ambientes de comércio passaram a ser veiculadas pela mídia (leiase jornais) utilizando o esporte enquanto tema. A estratégia, claro, era a de atrair a atenção através de ações que agradavam os torcedores-consumidores. Muitas casas comerciais cariocas auxiliavam o football através da promoção de jogos, doação de taças e reserva de espaço em lojas e mercados para exposição de uniformes esportivos das equipes locais. Afinal, auxiliar o esporte permitia a determinada empresa construir uma boa imagem, passando a visão aos consumidores de que em seu interior havia a preocupação com a saúde física e emocional dos adeptos do esporte.

Para muitos operários, no entanto, o apoio dado pelos diretores de fábricas (caso do Bangu) era visto como uma dádiva recebida. Porém, tais diretores exigiam relatórios que indicassem as aplicações, gastos e atividades desenvolvidas, controlando o desenvolvimento de tais agremiações esportivas. Tal controle estendeu-se a outras associações subsidiadas por fábricas em outros pontos do país, caso de São Paulo.

As iniciativas da Companhia Progresso (Bangu AC) de apoio ao futebol entre seus colaboradores teriam sido seguidas por outras companhias têxteis da cidade do Rio de Janeiro: Companhia de Fiação e Tecidos Carioca (Carioca Football Club, 1907), Fábrica Cruzeiro (Andarahy Athetico Club, 1909), Companhia Brazil Industrial (Paracambi Football Club, 1912), Companhia Confiança Industrial (Confiança Atlético Clube, 1915) e Fábrica Mavilis (Mavilis Football Club, 1915, em alusão às iniciais de Manuel Vicente Lisboa, um dos diretores da Companhia América Fabril e grande incentivador do futebol entre os funcionários da empresa).

Campos de Goytacazes, no norte fluminense, também assistiu à proliferação de uma série de agremiações de futebol, com destaque ao Goitacaz e ao Americano. $\mathrm{Na}$ região, diversos clubes emergiram em torno da economia açucareira e tiveram o aparato de usineiros. As empresas açucareiras cederam benefícios como a

\footnotetext{
${ }^{13} \mathrm{O}$ incremento das atividades de clubes passou a requerer um aprimoramento organizacional. Em cada unidade fabril incentivadora do esporte, foi estruturada uma diretoria, cujos membros tinham por função gerenciar as atividades do grêmio. A tendência era de que esses diretores fossem recrutados dentre os membros dos próprios quadros burocráticos da empresa como chefes, diretores e gerentes. Também passou a ser comum o(s) dono(s) da fábrica ou altos funcionários ocuparem posições de destaque na burocracia do time, como, por exemplo, presidente de honra, em sinal do reconhecimento dos sócios pelos serviços prestados ao clube.
} 
estruturação de campos para a prática, agregando funcionários e habitantes locais. Desta forma, surgiram agremiações como União e Aliança (Usina de Queimado), Ypiranga (Morro do Coco), Atlético (Goytacazes), Santo Antônio (Beco), Martins Laje (Martins Laje), Rio Preto (Morangaba), Palmeiras e Liberal (Cambaíba), Tamandaré (Santa Maria), Santa Cruz (Santa Cruz), Nacional (Saturnino Braga), Comercial (Conselheiro Josino), Ururaí e União de Ururaí (Ururaí), Cruzeiro (Poço Gordo), Estrela (Ponta da Cruz), Santo Eduardo, Esporte Clube Italva e Cardoso Moreira Futebol Clube. O apoio perdurou até a década de 1980, quando muitas das usinas entraram em processo de decadência. Com a crise, muitas das agremiações sucumbiram, demonstrando a dependência das mesmas em relação às usinas de açúcar e álcool.

Em diversos estatutos das associações esportivas do primeiro quartel do século $\mathrm{XX}$ analisados, consta a proibição de discussões políticas, sindicais ou religiosas. O artigo 74 dos estatutos dos Lanifícios Minerva (Rio de Janeiro), de 1921, por exemplo, estipulava que seria "vedado ao club envolver-se em manifestações e atos de caráter político" e que os sócios estariam "impedidos de tratar de assuntos políticos na sede social"14. Tais dispositivos demonstram os compromissos entre os subsidiados e patrocinadores dos clubes como uma forma de se evitar a participação dos integrantes das agremiações em greves e movimentos reivindicatórios, passando a imagem de uma relação amigável entre patrões e empregados.

Da mesma forma que no Rio de Janeiro-RJ, em São Paulo-SP o futebol passou a ser incorporado a diversas instituições fabris, caso do Juta Sant'Anna Football Club, que foi estruturado por funcionários da Companhia Nacional de Tecidos Juta (Fábrica Juta Sant'Anna) na década de 1910, no bairro do Brás. O time recebeu, de acordo com relatórios, total apoio da empresa, como suporte financeiro para a constituição de seu campo e sede, além de subsídios para manutenção.

Jorge Street, dono da Companhia Nacional de Tecidos de Juta (CNTJ), no bairro paulistano do Belenzinho, seguiu os passos da Companhia Progresso Industrial do Brasil, erguendo, entre 1911 e 1917, a Vila Maria Zélia para seus operários. Tudo indica que suas intenções eram as mesmas de outros centros produtivos. Para industriais como Nicolau Scarpa, também de São Paulo-SP, o patrocínio aos grêmios seria uma forma de resolver "os complexos problemas da questão social ao solucionar o conflito entre capital e trabalho" (RAGGO apud PEREIRA, 2000, p.181). A mesma iniciativa foi tomada pelo Cotonifício Crespi, pela Vidraçaria Santa Marina, pela Cigarros Sudan, pela Matarazzo e pela Companhia Lacta.

Em São Paulo-SP, os clubes da Light não foram diferentes de outros criados em fábricas, mas sua tendência era a de descentralizar as atividades esportivas entre seus colaboradores, não chegando a estabelecer um modelo padrão a ser seguido por

${ }^{14}$ Arquivo Nacional, SPDF, IJ - 759. 
suas associações esportivas. Desta forma, formaram-se pequenos e diversos núcleos recreativos entre as diversas seções e departamentos do conglomerado.

Companhias como a The São Paulo Tramway, Light and Power Company Limited e The São Paulo Gaz Company também incentivaram o futebol entre seus funcionários, chegando mesmo a ceder terrenos para a edificação de campos para a prática e sedes administrativas e recreativas.

Em 1920, as Indústrias Matarazzo apresentavam ramificações em várias partes do Brasil e também no exterior, produzindo bebidas, álcool, perfumes, sabão, velas, óleos diversos, gesso, entre outros produtos.

Mesmo com tamanha ampliação dos negócios, a concentração das decisões administrativas ficou a cargo de Francisco Matarazzo. E é a uma dessas resoluções que faço menção especial: a criação da Associação Atlética Matarazzo, fundada em 1914 e voltada basicamente para o incentivo ao futebol, embora a associação também organizasse bailes e festivais esportivos e recreativos: “[...] o presidente da S/A Indústrias Reunidas Francisco Matarazzo é, de direito, presidente honorário da Associação Atlética Matarazzo."15.

Um empregado, ao ser admitido na Matarazzo, tornava-se sócio, automaticamente, da Associação Atlética. As mensalidades variavam de acordo com as faixas salariais, descontadas em folha de pagamento. Tais contribuições, obrigatórias, livravam as Indústrias Matarazzo de subsídios com aluguéis da sede social e do campo de futebol. Próprio do comportamento concentrador de Francisco Matarazzo, a Associação Atlética gerenciava os grêmios das várias unidades das Indústrias Matarazzo. O futebol, por sua vez, foi uma atividade presente desde a fundação da Associação, que realizava campeonatos internos entre as diversas seções dos escritórios centrais. Deles (grêmios das Indústrias Matarazzo da capital e interior de São Paulo $^{16}$ ), saía o time principal que disputava os campeonatos internos das fábricas do estado de São Paulo.

Em 1924, na capital paulista, nasceu o Clube Atlético Juventos. Tanto o Juventus quanto o Bangu carioca se tornariam com o tempo, mais famosos que as próprias fábricas. No ano seguinte, 1925, Rodolfo Crespi cedeu ao seu clube de fábrica, o Juventus, amplo terreno situado à Alameda Javary, n. 117 (atual rua Javari). O local, até então utilizado como cocheira de cavalos, passou a servir à prática do futebol entre seus colaboradores.

\footnotetext{
${ }^{15}$ Estatutos da Associação Atlética Matarazzo, capítulo 1, artigo 3, de 18 de abril de 1932.

${ }^{16}$ A Associação Amália de Desportos Atléticos (AADA), fundada em 01 de janeiro de 1940, empresa localizada nos arredores da cidade paulista de Ribeirão Preto e ligada à S/A Indústrias Reunidas Francisco Matarazzo, tinha em seus estatutos o objetivo de promover a prática de todos os esportes, principalmente o futebol. Foi possível identificar em seus Estatutos a intenção de despolitização de seus associados, pois, conforme Capítulo II, artigo 8: "são deveres dos associados: [...] d) abster-se de manifestação ou discussão de natureza política, religiosa ou de classes, nas dependências da associação".
} 
No primeiro quartel do século XX, tornaram-se frequentes campeonatos internos em municípios do estado São Paulo com nomes de fábricas, indício do patrocínio dado pelas mesmas para a organização e viabilização de equipes operárias, o que, além de ser uma forma de divulgação do nome das empresas protetoras (assim como de seus produtos) promoveu de forma crescente a popularização de atividades esportivas (caso do futebol). Ou seja, para o empregador, uma forma de representação da fábrica e interferência/disciplina no tempo do colaborador (controle sobre o tempo livre dos trabalhadores), além de passar a visão de uma empresa vencedora e fazer propaganda de seus produtos. Para o trabalhador, os objetivos eram outros como de crescimento e reconhecimento por parte da fábrica, além de ganhos pessoais e possibilidades de lazer. No entanto, destaca-se um objetivo pouco explícito: retirar os operários das discussões e organizações sindicais. Ao assumirem o papel de mantenedores dos clubes esportivos, empresários acentuaram a dependência dos trabalhadores em relação a eles, sendo que o controle sobre tais colaboradores não ficou restrito à fábrica, mas à vida privada dos mesmos, incluindo moradia e lazer (fora dos limites da linha de produção).

Nos anos 1920 era difícil apontar uma indústria da capital paulista que não apresentasse um time ou um clube de futebol.

Patrocinar um clube passou a significar a criação de amizade com os colaboradores, o que teria contribuído para a desmobilização da luta sindical ao reforçar a identidade trabalhador-fábrica, embora o fenômeno não tenha se limitado ao futebol, uma vez que os diversos clubes passaram a promover encontros dançantes, concursos de beleza e bailes carnavalescos. Mais do que uma cultura operária, uma cultura fabril. Uma espécie de coronelismo esportivo que permitia a diminuição da distância dos empresários em relação aos seus colaboradores e dependentes.

Joel Rufino Santos (1981, p.22) aponta que os empresários, ao promoverem o futebol no interior das fábricas, procuraram criar um elemento disciplinador através da prática: "[...] como a uma criança que se manda brincar para queimar energias, mandados jogar futebol".

\section{Considerações Finais}

O futebol moderno, inventado pelos ingleses, separou o jogo do rito. Ele deve ter sido visto por operários ingleses e brasileiros como a possibilidade de reparação das injustiças, uma vez que no campo econômico isto parecia - e talvez continue a parecer - impossível.

Berço da produção industrial, o futebol significa trabalho em equipe, diferenciando a fábrica moderna da produção familiar artesanal. Tal qual uma fábrica que 
exige disciplina do trabalhador, do jogador de futebol também se espera que siga as instruções de um treinador se não quiser perder seu posto de atuação. O respeito à hierarquia do clube também deve ser levado em consideração (caso o jogador como o trabalhador - não queira perder sua vaga, quase sempre provisória).

Assim como a produção industrial, o todo deve estar voltado para que se atinja o objetivo: produzir e defender o produzido de qualquer revés, segundo técnicas e regulação. Assim como no sistema produtivo no futebol alguns realizam, outros pensam e dirigem e outros colhem os resultados.

O próprio fato de se introduzir uma arbitragem (1881) e um apito (1888) nos jogos deste esporte, representou uma forma de regulamentar as ações e o tempo, atuação próxima do Estado, o que frustra a realidade, como que contendo o lucro a todo custo e renovando o jogo ao atuar no sentido de revitalizar a produção e limitar o prazer imediato. Isto significa dizer que no futebol o árbitro principal deve atuar em prol da produção já que fazer cera (adiar o fluxo do jogo), desperdício e poupança são ações próprias do homem no processo produtivo.

Necessário se faz reconhecer que o até então esporte das elites tornou-se uma poderosa expressão dos setores sociais mais empobrecidos, em uma disseminação impressionante, talvez por ser este esporte o único que inspire a possibilidade da quebra das hierarquias sociais.

Ao engendrar-se na vida do brasileiro, o futebol passou a expressar uma riqueza simbólica. Ao identificar-se como popular, o futebol teria trazido ao brasileiro a possibilidade de jogar através de normas e regras.

A busca de patrocinadores para a prática - caso dos primeiros clubes operários também aponta para uma tendência do brasileiro: a de se sentir protegido e depender de quem considera superior.

A prática do esporte em uma fábrica propicia, em normalidade, um sentimento de grupo, em que pese a existência de uma hierarquia existente dentro de seu corpo. Desta forma, as tensões internas tendem a diminuir, encobrindo as contradições.

Levando-se em consideração que a prática do futebol seja disciplinadora, os clubes operários estruturados a partir das fábricas reproduziram a dominação existente no interior do ambiente produtivo. Ou seja, oferecer subsídios a um clube de futebol operário de forma assistencialista e com interesses disciplinadores foi uma forma encontrada por empresários de esvaziar movimentos reivindicatórios e controlar a vida dos trabalhadores. Mas, de certa forma, o futebol operário estruturou uma resistência à dominação imposta pelo cotidiano, afinal, creio, a ação humana não deve ser vista apenas sobre as relações de produção. Se assim fosse, não restaria qualquer manifestação de autonomia humana.

Talvez mais do que agirem como mecenas no que tange ao futebol, industriais tenham sido induzidos pelos trabalhadores a financiá-lo. 
Patrocinados pelas direções fabris, as mesmas exigiam certo retorno dos investimentos, fiscalizando as atividades através de balancetes e relatórios. Uma forma de controle.

É provável que inúmeros clubes de fábrica tenham surgido de simples batebolas, ou seja, de partidas de futebol improvisadas, disputadas na rua ou no pátio da fábrica durante o intervalo para o almoço entre aqueles trabalhadores que se dispusessem a jogá-lo. Certo, no entanto, é que, aos poucos, a brincadeira foi ganhando maior organização.

Times operários pressupõem identidade entre os participantes de vida semelhante (trabalhadores), portanto, explorados pelo sistema. Neste sentido, a presença da fábrica (através do financiamento para aquisição de equipamentos, presença de diretores da empresa na estrutura administrativa do clube, nome da agremiação, fornecimento de campo para a prática, entre outros) indica uma interferência reguladora, ferindo resistências e autonomia.

O estímulo ao lazer para os operários pode - como acredito que o fez evitar contestações às condições de trabalho oferecidas por várias empresas por proporcionar aos jogadores operários melhores condições do que aos demais operários. Em muitos clubes ligados a empresas o operário-jogador estava impedido de associar-se aos sindicatos. Porém, não se pode afirmar que o controle foi total. Para os trabalhadores pode ter significado, não só a diversão, mas a possiblidade de ascensão na fábrica a cargos mais elevados e mais bem remunerados.

Vale lembrar que a consolidação do futebol como febre operária e, posteriormente, como fator de identidade nacional através de ações governamentais e da mídia, deixou o legado do imaginário. Um bom e apreciado imaginário. Afinal, talvez Joé Miguel Wisnik (2008, p.11) tenha razão ao afirmar que "viver o futebol dispensa pensá-lo, e, em grande parte, é essa dispensa que se procura nele".

\section{FOOTBALL: BETWEEN LEISURE AND CONTROL}

ABSTRACT: Modern football is linked to industrialism. I venture to argue that contemporary western human life looks like football matches: clashes, measured time, fights for ownership and acceptance, supporters acting as political parties, thesis discussions, improvisations, symbologies of socialization, theatricalization of social life, among others. It is necessary to understand how the Brazilian appropriated the sport, as if taking it from the wealthier layers who had introduced it in the country. In the first decades of the twentieth century, the Brazilian labor movement was noisy. The emerging Brazilian industrial bourgeoisie, worried about the proletarian union mobilizations, would have made use of less harsh mechanisms such as supporting and financing the sport which had fallen into workers' hands: 
football. In order to do so, the historical and social rescue of documents from various associations allows us to observe patronage interferences in club development, controlling them directly and/or indirectly. Since then, the sport has followed its trajectory, permeating policies and adjusting personal conflicts.

KEYWORDS: Soccer. Industrialism. Social Control.

\section{FÚTBOL: ENTRE EL OCIO Y EL CONTROL}

RESUMEN: El fútbol moderno se vincula al industrialismo. Me atrevo a decir que la vida humana occidental contemporánea aparenta partidos de fútbol: los embates, el tiempo medido, las luchas por la titularidad y la aceptación, las torcidas actuando como partidos politicos, discusiones de tesis, improvisaciones, simbologías de socialización, teatralización de la vida social, entre otros. Se hace necesario entender cómo el brasileño se apropió del deporte, como que tomando de los estrados más ricos que lo introdujeron en el país. En las primeras décadas del siglo $X X$, el movimiento obrero brasileño se colocó de forma ruidosa. A pesar de la acción represiva gubernamental, la naciente burguesía industrial brasileña, inquieta ante las movilizaciones sindicales proletarias, habria hecho uso de mecanismos menos duros como apoyar y financiar el deporte que habia caido en las gracias obreras: el fútbol. Por lo tanto, la recuperación histórica-social de documentos de diversas agremiaciones permite observar interferencias patronales en el desarrollo clubista, controlándolas directa y / o indirectamente. Desde entonces, el deporte siguió su trayectoria, involucrando gran parte de la sociedad brasileña, permeando políticas $y$ ajustando conflictos personales con el mundo vivido, propio del imaginario social.

PALABRAS CLAVE: Fútbol. Control. Imaginario social.

\section{REFERÊNCIAS}

AQUINO, Rubim Santos Leão. Futebol, uma paixão nacional. Rio de Janeiro: Jorge Zahar, 2002.

ANTUNES, Fátima M. O futebol nas fábricas. Revista USP, São Paulo, Dossiê Futebol, n. 22, p.104, 1994.

BATALHA, Cláudio H. M. Cultura Associativa no Rio de Janeiro. In: BATALHA, Cláudio H. M.; SILVA, Fernando T.; FORTES, Alexandre (Org.). Culturas de classe: identidade e diversidade na formação do operariado. Campinas: Ed. Unicamp, 2004. 
BOURDIEU, Pierre. Sobre a televisão. Rio de Janeiro: Jorge Zahar, 1997.

BRETAS, Marcos Luís. A guerra das ruas: povo e polícia na cidade do Rio de Janeiro. Rio de Janeiro: Arquivo Nacional, 1997.

ELIAS, Norbert; DUNNING, Eric. Deporte y ocio en el processo de la civilización. 2. ed. Cidade do México: Fondo de Cultura Económica, 1995.

ELIAS, Norbert; DUNNING, Eric. A busca da excitação. Lisboa: DIFEL, 1992a.

ELIAS, Norbert; DUNNING, Eric. Deporte y ocio en el processo de la civilización. Cidade do México: Fondo de Cultura Económica, 1992b.

FRANCO JÚNIOR, Hilário. A dança dos deuses: futebol, sociedade e cultura. São Paulo: Companhia das Letras, 2007.

MARIVOET, S. Inclusão Social no e pelo Desporto. Um desafio do Século XXI. In PINTO, P. M. (Coord.). Olímpico. Os jogos num percurso de valores e de significados. Porto: Edições Afrontamento, p.91-98, 2013.

. Aspectos Sociológicos do Desporto. Lisboa: Livros Horizonte, 2002.

NORONHA, Sérgio (Org.). Almanaque dos esportes. Rio de Janeiro: Rio Gráfica, 1975.

PEREIRA, Leonardo Footballmania: uma história social do futebol no Rio de Janeiro, 1902-1938. Rio de Janeiro: Nova Fronteira, 2000.

RIGAUER, Bero. Sport und Arbeit. [S. 1.: s. n.]1969.

ROSENFELD, Anatol. Negro, macumba e futebol. São Paulo: Edusp, Unicamp, Perspectiva, 1993. (Coleção Debates, v. 258).

SANTOS, Joel Rufino. História política do futebol brasileiro. São Paulo: Brasiliense, 1981. THOMPSON, Edward Palmer. Tempo, disciplina de trabalho e capitalismo industrial. In: Costumes em comum. São Paulo: Companhia das letras, 1998.

. A formação da classe operária inglesa. Rio de Janeiro: Paz e Terra, 1987. v.2.

WISNIK, José M. Veneno Remédio - o futebol e o Brasil. São Paulo: Cia. das Letras, 2008.

Recebido em 26/11/2017.

Aprovado em 13/12/2018. 
